\title{
Longer prolapsed rectum length increases recurrence risk after Delorme's procedure
}

\author{
Taro Tanabe, Emi Yamaguchi, Takuya Nakada, Risa Nishio, Kinya Okamoto, Tetsuo Yamana \\ Department of Coloproctology, Tokyo Yamate Medical Center, Tokyo, Japan
}

Purpose: Risk factors for recurrence of rectal prolapse after surgery remain unclear. Delorme's procedure is often selected for relatively small-sized rectal prolapse, but there are few reports discussing the association between prolapsed rectum length and prolapse recurrence after Delorme's procedure. We hypothesized that patients with longer rectal prolapses are at a higher risk of recurrence after Delorme's procedure.

Methods: The study population comprised patients with rectal prolapse who underwent Delorme's procedure between January 2014 and December 2019 at Tokyo Yamate Medical Center. We extracted data on patient age, sex, body mass index, previous history of anal surgery, previous history of surgery for rectal prolapse, and length of prolapse, to identify risk factors for prolapse recurrence.

Results: Altogether, 96 patients were eligible for analysis. The median length of the prolapsed rectum was $3.0 \mathrm{~cm}$ (range, $1.0-6.6 \mathrm{~cm}$ ). Twenty-four patients (25.0\%) experienced recurrence after Delorme's procedure after a median of 7.5 months (interquartile range, 3.2-20.9 months). Multivariate analysis revealed that longer prolapsed rectum length increased the risk of recurrence after Delorme's procedure (hazard ratio, 6.28; 95\% confidence interval, $1.83-21.50 ; \mathrm{P}<0.001$ ).

Conclusion: The length of the prolapsed rectum should be measured before Delorme's procedure for rectal prolapse, because length is associated with a risk of recurrence after the surgery.

Keywords: Delorme's procedure; Recurrence; Rectal prolapse

\section{INTRODUCTION}

Rectal prolapse is a benign condition in which the rectum protrudes outside the anus; this occurs mainly in elderly women [1]. Although rarely fatal, it can lead to distressing symptoms that have a significant impact on the patient's quality of life [2]. Surgery is the only curative treatment. However, despite multiple randomized prospective trials, there is still no consensus on the standard procedure for rectal prolapse repair [3-6].

Surgery for rectal prolapse has been broadly categorized into 2

Received: Dec 3, 2020 - Revised: Apr 29, 2021 - Accepted: May 1, 2021

Correspondence to: Taro Tanabe, M.D.

Department of Coloproctology, Tokyo Yamate Medical Center, 3-22-1

Hyakunin-cho, Shinjuku-ku, Tokyo 1690073, Japan

Tel: +81-3-3364-0251, Fax: +81-3-3364-5663

E-mail: tatanabe1209@outlook.jp

ORCID: https://orcid.org/0000-0001-8128-5519

(c) 2022 The Korean Society of Coloproctology

This is an open-access article distributed under the terms of the Creative Commons Attribution NonCommercial License (https://creativecommons.org/licenses/by-nc/4.0) which permits unrestricted noncommercial use, distribution, and reproduction in any medium, provided the original work is properly cited. procedures; the abdominal and the perineal approach. Each approach has its own advantages and drawbacks. The perineal approach is considered suitable for frail and elderly patients because it can be performed under local or spinal anesthesia, with lower morbidity [7]. It is also recommended for young male patients because pelvic nerve injury can be avoided, which preserves sexual or urinary function [8]. Notwithstanding the advantages, a higher recurrence rate with the perineal approach has been reported as compared to the abdominal approach $[2,7]$.

Delorme's procedure is one of the best-known perineal operations for full-thickness rectal prolapse; it involves sleeve resection of the mucosa and plication of the rectal wall muscle. Generally, surgeons prefer this procedure for short rectal prolapse $[9,10]$. However, few studies have examined the association between the length of the prolapsed rectum and recurrence after Delorme's procedure. Therefore, we aimed to examine whether the length of the prolapsed rectum was associated with recurrence after the Delorme's procedure in order to predict patients with a higher risk of recurrence before Delorme's procedure. 


\section{METHODS}

\section{Study population and design}

We performed a retrospective review of all consecutive patients who underwent surgery for full-thickness rectal prolapse at the Tokyo Yamate Medical Center from January 2014 to December 2019. The study population comprised all patients on whom Delorme's procedure was performed. Patients with short-segment of full-thickness rectal prolapse underwent Delorme's procedure in accordance with clinical practice guidelines [11, 12]. Patients with a history of treatment failure after a previous operation for rectal prolapse were also included. Finally, patients whose medical records were incomplete were excluded from the analysis.

This retrospective study was approved by the Institutional Review Board of the Tokyo Yamate Medical Center (No. J-075), and the requirement to obtain informed consent was waived.

\section{Data collection}

The data that were retrospectively obtained through the review of a prospectively generated database were as follows: age, sex, body mass index, previous history of anal surgery, previous history of surgery for rectal prolapse, and length of the prolapsed rectum. Length of the prolapsed rectum was defined as the length between the apex of the prolapse and the level of the perineum while straining in the squatting position. Follow-up data was documented prospectively until recurrence occurred, or until the cutoff date of the study, i.e., March 2020. Recurrence was defined as anatomical recurrence of external full-thickness prolapse of the rectal wall and diagnosed clinically at outpatient clinic.

\section{Perioperative management}

All patients had the length of prolapsed rectum measured while straining. Preoperative defecography was performed on patients for whom an accurate length of the prolapsed rectum could not be measured. Patients who were suspected as having intraluminal malignancy because of their symptoms such as anemia, bloody stool, or history of body weight loss, underwent preoperative colonoscopy to exclude intraluminal pathology. Similarly, patients who were suspected as having poor sphincter function by digital exam underwent preoperative anal manometry to evaluate rectal physiology. Delorme's procedure was indicated for patients who had a prolapsed rectum sized $<5 \mathrm{~cm}$ without pelvic organ prolapse or for patients who could not tolerate general anesthesia. Preoperatively, all patients received bowel preparation, and intravenous antibiotics were administered prophylactically. All patients had the surgery under hyperbaric spinal anesthesia. During the surgery, a mucosectomy was performed until greater than twice the length of the prolapsed rectum was obtained. The patients were followed up 3 weeks after surgery and every 3 months thereafter.

\section{Statistical analysis}

The outcome was to determine the clinicopathological risk factors for recurrence of full-thickness rectal prolapse after Delorme's procedure. Recurrence-free time (RFT) was defined as the period between the date of rectal prolapse surgery and the date of recurrence. Kaplan-Meier analysis was used to estimate RFT, and survival curves were compared using the log-rank test. Multivariable Cox proportional hazards regression models were subsequently fitted to evaluate factors independently associated with RFT. Patient age, sex, length of the prolapsed rectum, and variables found to have a P-value of $<0.20$ in univariate analysis were included in the multivariate analysis models $[8,13,14]$. Results are presented as hazard ratios (HRs) and 95\% confidence intervals (CIs). All statistical analyses were performed using the JMP15 software program (SAS Institute Japan Ltd., Tokyo, Japan).

\section{RESULTS}

The details of our study cohort are summarized in Fig. 1. During the study period, a total of 104 patients underwent Delorme's procedure for rectal prolapse, with a median follow-up time of 6.4 months (interquartile range [IQR], 3.2-13.4 months). Eight patients were excluded due to missing data on prolapsed rectum length. Accordingly, the final study population consisted of $96 \mathrm{pa}-$ tients.

Baseline characteristics of patients in this study are shown in Table 1. A total of 82 female patients (85.4\%) and 14 male (14.6\%), with a median age of 78.5 years (IQR, 72-84.5 years) were enrolled. Among the 96 patients, 24 patients had undergone previous surgery for rectal prolapse; laparoscopic rectopexy $(n=8)$, Gant-Miwa-Thiersch procedure $(\mathrm{n}=3)$, and Delorme's procedure $(\mathrm{n}=13)$. Sixteen patients had undergone previous anal surgery; 12 cases had surgery for hemorrhoids, 3 cases for anal fistula, and 1 case for rectal cancer (intersphincteric resection). The median prolapsed rectal length was $3.0 \mathrm{~cm}$ (range, $1.0-6.6 \mathrm{~cm}$ ).

No mortality occurred during the follow-up period. One patient developed anal stricture after surgery and required bougie dilation. No other complication including sexual or urinary dysfunction was reported.

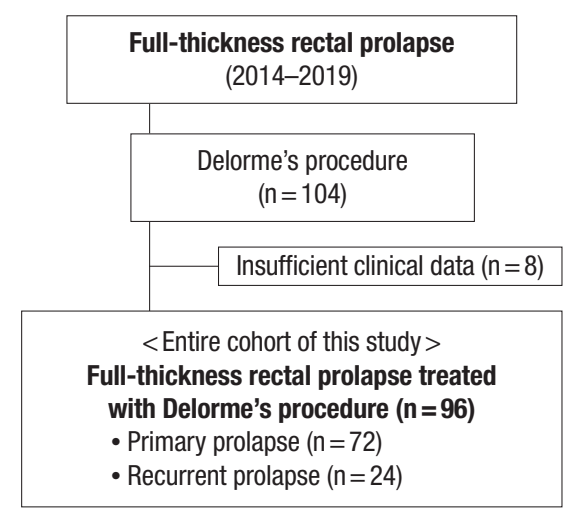

Fig. 1. Inclusion criteria of the current study cohort. 
Table 1. General information of patients $(n=96)$

\begin{tabular}{lc}
\hline Characteristic & Value \\
\hline Sex & $14(14.6)$ \\
Male & $82(85.4)$ \\
Female & \\
Age (yr) & $16(16.7)$ \\
$<65$ & $80(83.3)$ \\
$\geq 65$ & \\
Body mass index & $11(11.5)$ \\
Under weight & $74(77.1)$ \\
Normal & $11(11.5)$ \\
Preobese & $3.0(1.0-6.6)$ \\
Length of prolapsed rectum (cm) & \\
Previous anal surgery & $22(22.9)$ \\
Yes & $74(77.1)$ \\
No & \\
Previous surgery for rectal prolapse & $22(22.9)$ \\
Yes & $74(77.1)$ \\
No & $60(39-89)$ \\
Operating time (min) & $6(4-19)$ \\
Hospital stay (day) & $6.5(1-62)$ \\
Follow-up (mo) & \\
\hline
\end{tabular}

Values are presented as number (\%) or median (range).

\section{Recurrence after Delorme's procedure}

Among the 96 patients, full-thickness rectal prolapse recurrences occurred in 26 patients $(27.1 \%)$ at a median of 7.5 months (range, 1-62 months). After recurrence, 4 patients underwent a revised Delorme's procedure, 9 received a laparoscopic rectopexy, 9 received Thiersch procedure, and 4 refused further surgery.

In univariate analysis, prolapsed rectum length of $\geq 3 \mathrm{~cm}$ was significantly associated with prolapse recurrence (42\% vs. $7 \%$, $\mathrm{P}<0.001$; Fig. 2). Patients with shorter length of prolapsed rectum experienced recurrence within 14 months of surgery. In contrast, there was no definitive pattern for recurrence in patients with longer prolapses. No other significant predictors for recurrence were revealed.

In multivariate analysis, prolapsed rectum length of $\geq 3 \mathrm{~cm}$ was found to be independently associated with prolapse recurrence after Delorme's procedure (HR, 6.28; 95\% CI, 1.83-21.5; $\mathrm{P}<0.001$ ) (Table 2 ). Advanced age and being female were not significantly associated with recurrence in this study.

\section{DISCUSSION}

The aim of the present study was to investigate the association between the length of prolapsed rectum and recurrence of rectal prolapse. We demonstrated that patients with a prolapse length of

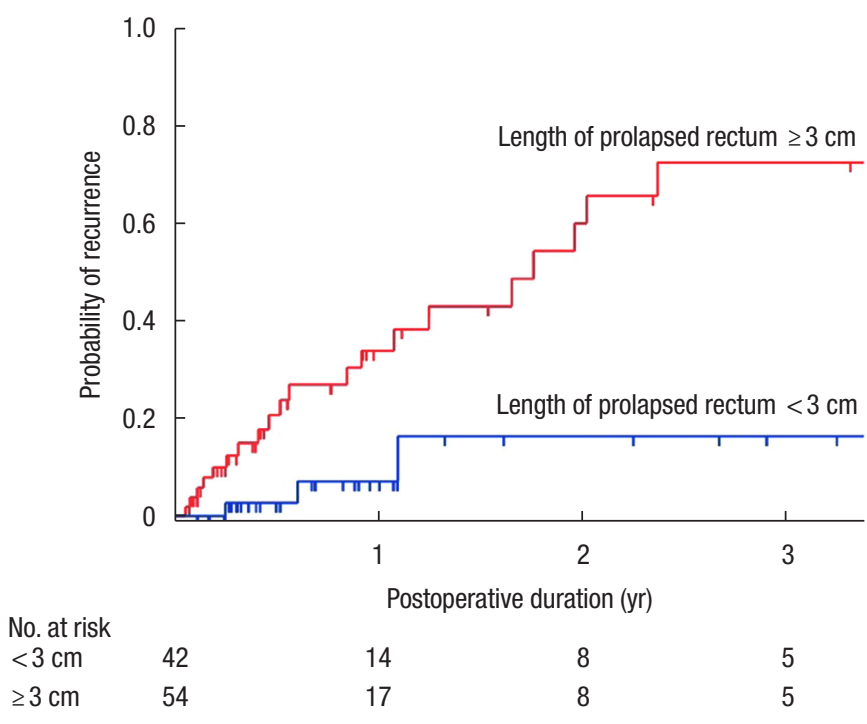

Fig. 2. Kaplan-Meier analysis of the risk of recurrent rectal prolapse after surgery depending on the length of prolapse.

$\geq 3 \mathrm{~cm}$ had a significantly higher risk of recurrence after Delorme's procedure. In previous studies, although the difference was not significant, patients with long rectal prolapses had a higher rate of relapse than patients with smaller prolapses $[8,15]$. To our knowledge, this is the first study to demonstrate the relationship between the length of rectal prolapse and recurrence rate after Delorme's procedure. While treating patients with long rectal prolapses, it can be better to have alternative options for surgery such as rectopexy or Altemeier surgery.

In contrast to previous studies, our study did not reveal a significant association between advanced age and increased risk of recurrence [8]. Elderly patients generally have a weak pelvic floor that contributes to recurrence after Delorme's procedure $[16,17]$. In our study, more than $80 \%$ of patients were over 65 years of age. The relatively low number of young people in this current study did not significantly increase the risk of prolapse recurrence.

Another important finding of this study was the low morbidity and complication rate after Delorme's procedure. Despite $25 \%$ of patients have had previous surgery for rectal prolapse, there were no reported cases of mortality, sexual or urinary dysfunction. With the development of laparoscopic surgery, although the abdominal approach now allows performing procedures with greater safety, it is yet to be determined whether the abdominal approach is the safest approach for patients with previous rectal prolapse surgery. Our study demonstrated that the perineal approach can be safely performed even in patients with previous surgery.

Previous studies reported that the rate of recurrence after Delorme's procedure ranged from $9.6 \%$ to $29.7 \%[6,8,13-15,18-21]$. The rate of recurrence in this current study was $27.1 \%$, which is relatively higher than previous reports. Two factors may account 
Table 2. Univariate and multivariate analyses of factors affecting recurrence after Delorme's procedure

\begin{tabular}{|c|c|c|c|c|c|}
\hline \multirow{2}{*}{ Variable } & \multirow{2}{*}{$\begin{array}{c}\text { Recurrence rate } \\
(\%)\end{array}$} & \multirow{2}{*}{$\begin{array}{c}\text { Univariate analysis, } \\
\text { P-value }\end{array}$} & \multicolumn{3}{|c|}{ Multivariate analysis } \\
\hline & & & Hazard ratio & $95 \% \mathrm{Cl}$ & P-value \\
\hline \multicolumn{6}{|l|}{ Sex } \\
\hline Female & 28.4 & & 2.58 & $0.73-9.03$ & 0.139 \\
\hline \multicolumn{6}{|l|}{ Age (yr) } \\
\hline \multicolumn{6}{|l|}{ Body mass index } \\
\hline Under weight & 0 & 0.408 & & & \\
\hline Normal & 28.1 & & & & \\
\hline Preobese & 45.5 & & & & \\
\hline \multicolumn{6}{|c|}{ Previous anal surgery } \\
\hline No & 29.0 & 0.142 & Reference & & \\
\hline Yes & 18.3 & & 0.63 & $0.19-2.18$ & 0.471 \\
\hline \multicolumn{6}{|c|}{ Previous surgery for rectal prolapse } \\
\hline No & 23.3 & 0.829 & & & \\
\hline Yes & 29.8 & & & & \\
\hline
\end{tabular}

$\mathrm{Cl}$, confidence interval.

for the high rate of recurrence in our study. Firstly, our cohort includes a large number of elderly patients compared with the demographics of previous studies. Elderly patients with rectal prolapse have poor sphincter function, which contributes to a higher risk of recurrence. Secondly, 24 of the 96 patients (25.0\%) had undergone previous surgery for rectal prolapse. Failure of previous rectal prolapse surgery may indicate a more severe prolapse, which has a higher risk of recurrence.

Our study has several limitations. First, because the study was retrospective in design, selection bias may exist. Second, although the sample size in this study is the largest to be reported in a study on risk factors after Delorme's procedures, the sample size was still relatively small. Third, not all patients underwent the same initial metrics evaluation; some underwent defecography, others received anal manometry, and others underwent a colonoscopy. Such evaluations may reveal factors, such as sphincter dysfunction, which are associated with prolapse recurrence after surgery. Finally, a relatively short median follow-up of 6.5 months may underestimate the rate of recurrence after Delorme's procedure.

In conclusion, we found an association between recurrence after Delorme's procedure and rectal prolapse length. Therefore, the prolapsed rectum should be measured prior to performing Delorme's procedure. A prospective study is required to better determine other predictors of prolapse recurrence after Delorme's procedure.

\section{CONFLICT OF INTEREST}

No potential conflict of interest relevant to this article was reported.

\section{FUNDING}

None.

\section{ACKNOWLEDGMENTS}

The authors thank Shari J. Berman from Japan Language Forum for constructive support with the manuscript.

\section{REFERENCES}

1. Wijffels NA, Collinson R, Cunningham C, Lindsey I. What is the natural history of internal rectal prolapse? Colorectal Dis 2010;12: 822-30.

2. Bordeianou L, Hicks CW, Kaiser AM, Alavi K, Sudan R, Wise PE. Rectal prolapse: an overview of clinical features, diagnosis, and patient-specific management strategies. J Gastrointest Surg 2014; 18:1059-69.

3. Karas JR, Uranues S, Altomare DF, Sokmen S, Krivokapic Z, 
Hoch J, et al. No rectopexy versus rectopexy following rectal mobilization for full-thickness rectal prolapse: a randomized controlled trial. Dis Colon Rectum 2011;54:29-34.

4. Rothenhoefer S, Herrle F, Herold A, Joos A, Bussen D, Kieser M, et al. DeloRes trial: study protocol for a randomized trial comparing two standardized surgical approaches in rectal prolapse: Delorme's procedure versus resection rectopexy. Trials 2012;13:155.

5. Senapati A, Gray RG, Middleton LJ, Harding J, Hills RK, Armitage NC, et al. PROSPER: a randomised comparison of surgical treatments for rectal prolapse. Colorectal Dis 2013;15:858-68.

6. Emile SH, Elbanna H, Youssef M, Thabet W, Omar W, Elshobaky A, et al. Laparoscopic ventral mesh rectopexy vs Delorme's operation in management of complete rectal prolapse: a prospective randomized study. Colorectal Dis 2017;19:50-7.

7. Riansuwan W, Hull TL, Bast J, Hammel JP, Church JM. Comparison of perineal operations with abdominal operations for fullthickness rectal prolapse. World J Surg 2010;34:1116-22.

8. Fazeli MS, Kazemeini AR, Keshvari A, Keramati MR. Delorme's procedure: an effective treatment for a full-thickness rectal prolapse in young patients. Ann Coloproctol 2013;29:60-5.

9. Altomare DF, Binda G, Ganio E, De Nardi P, Giamundo P, Pescatori $\mathrm{M}$, et al. Long-term outcome of Altemeier's procedure for rectal prolapse. Dis Colon Rectum 2009;52:698-703.

10. Elagili F, Gurland B, Liu X, Church J, Ozuner G. Comparing perineal repairs for rectal prolapse: Delorme versus Altemeier. Tech Coloproctol 2015;19:521-5.

11. Bordeianou L, Paquette I, Johnson E, Holubar SD, Gaertner W, Feingold DL, et al. Clinical practice guidelines for the treatment of rectal prolapse. Dis Colon Rectum 2017;60:1121-31.

12. van der Schans EM, Paulides TJC, Wijffels NA, Consten ECJ.
Management of patients with rectal prolapse: the 2017 Dutch guidelines. Tech Coloproctol 2018;22:589-96.

13. Hyun K, Yoon SG. Comparison of Delorme-Thiersch operation outcomes in men and women with rectal prolapse. Ann Coloproctol 2019;35:262-7.

14. Watts AM, Thompson MR. Evaluation of Delorme's procedure as a treatment for full-thickness rectal prolapse. Br J Surg 2000;87: 218-22.

15. Placer C, Enriquez-Navascués JM, Timoteo A, Elorza G, Borda N, Gallego L, et al. Delorme's Procedure for complete rectal prolapse: a study of recurrence patterns in the long term. Surg Res Pract 2015;2015:920154.

16. Goldstein SD, Maxwell PJ 4th. Rectal prolapse. Clin Colon Rectal Surg 2011;24:39-45.

17. Harmston C, Jones OM, Cunningham C, Lindsey I. The relationship between internal rectal prolapse and internal anal sphincter function. Colorectal Dis 2011;13:791-5.

18. Watkins BP, Landercasper J, Belzer GE, Rechner P, Knudson R, Bintz $\mathrm{M}$, et al. Long-term follow-up of the modified Delorme procedure for rectal prolapse. Arch Surg 2003;138:498-502.

19. Marchal F, Bresler L, Ayav A, Zarnegar R, Brunaud L, Duchamp C, et al. Long-term results of Delorme's procedure and Orr-Loygue rectopexy to treat complete rectal prolapse. Dis Colon Rectum 2005;48:1785-90.

20. Tsunoda A, Yasuda N, Yokoyama N, Kamiyama G, Kusano M. Delorme's procedure for rectal prolapse: clinical and physiological analysis. Dis Colon Rectum 2003;46:1260-5.

21. Mahmoud SA, Omar W, Abdel-Elah K, Farid M. Delorme's procedure for full-thickness rectal prolapse: does it alter anorectal function. Indian J Surg 2012;74:381-4. 